\title{
Neo-Lamarckism and Neo-Darwinism ${ }^{\dagger}$
}

\author{
L.H. Bailey
}

It is difficult to accept the hypothesis of organic evolution in the abstract. In the first place, there must be some reason for the operation of a law of transformation or development; and this is found in the ever-changing physical or external conditions of existence, which are more or less opposed to established organisms. And it may also be said that the very fact of the increase of organisms through multiplication must impose new conditions of competition upon every succeeding generation. Again, it is necessary to conceive of some means or machinery by which the process of evolution is carried forward. It was long known that all species vary, that is, that no two individuals in nature are exactly alike; yet there was lacking any hypothesis to show either why these varieties appear or how it is that some become permanent and some do not. The first scientific explanation of the process of evolution was that made in 1809 by the now famous Lamarck. He saw two factors which, he thought, were concerned in the transformation of species-the habitat and the habit. The habitat is the condition in which the organism lives, the environment. This environment, subject to change with every new individual, calls for new habits to adapt the organism to the new needs-inducing greater exercise of some powers or organs and less exercise of others. This greater or less use gradually strengthens or enfeebles the organ concerned, and the modifications thus acquired are preserved "through heredity to the new individuals that are produced by them, provided the changes are common to the two sexes, or to those that have produced these new individuals." There are three things to be considered in this hypothesis: 1. Changes in environment or the conditions of life react upon organisms in the direction of their needs or functions. 2. Organs or powers thus affected are modified to satisfy the new demands. 3. The modifications acquired by the individual are hereditary. This, then, is Lamarckism-that the controlling factor or process in evolution is functional, and that acquired characters are readily transmissible.
It is important that I still repeat Lamarck's belief in the transmission of a character obtained by any individual during its own lifetime, for this is the starting point of the definition of an "acquired character" concerning the hereditability of which the scientific world is now rent. "All that nature has caused individuals to acquire or lose through the influence of the circumstances to which their race has been for a long time exposed," says Lamarck, "it preserves," etc. And again, "Every change acquired in an organ by a habitual exercise sufficient to have brought it about, is preserved thereafter through heredity," etc. We shall presently observe how far this definition of an acquired character has been maintained by recent philosophers.

Just fifty years after the publication of Lamarck's theory, Darwin proposed a hypothesis which has had a greater influence upon the habit of scientific thought than any enunciation since the promulgation of inductive philosophy. Darwin, like Lamarck, saw that all forms of life vary; and like him, too, he perceived that there must be a fierce struggle for place or existence amongst the individuals of the rapidly succeeding generations. This variation and struggle are particularly apparent in cultivated plants; and Darwin saw that the gardener selects the best, and thereby "improves" the breed. "Can it, then, be thought improbable," says Darwin, "seeing that variations useful to man have undoubtedly occurred, that other variations useful in some way to each being in the great and complex battle of life, should occur in the course of many successive generations? If such do occur, can we doubt (remembering that many more individuals are born than can possibly survive) that individuals having any advantage, however slight, over others, would have the best chance of surviving and of procreating their kind? This preservation of favorable individual differences and variations, and the destruction of those which are injurious, I have called Natural Selection, or the Survival of the Fittest." This, then, is Darwinism - that the controlling

\footnotetext{
†Published in "The American Naturalist", vol. 28, 1894, p. 661-678.
} 
factor or process in evolution is selective: the survival, in the struggle for existence, of those individuals which are best fitted to survive. But while this is the naked core of Darwinism, there are various correlative or incidental hypotheses attached to it. Darwin, for instance, accepted in some degree the views of Lamarck as to the importance of functional characters; he considered that sexual selection, or the choice exercised in securing mates, is often an important factor in modifying species; he thought that variation is induced by the modifications of environment, or the "changed conditions of life;" and he was a firm believer in the hereditability of acquired characters. It is around these two great hypotheses - the functional or Lamarckian on the one hand, and the selective or Darwinian upon the other-in various forms and modifications, that the discussions of the philosophy of organic nature are at present revolving.

Before leaving the subject of Darwinism, I wish to touch upon Darwin's view of the cause of variation and his belief in the transmission of acquired characters. We shall presently see that the rehabilitation of the theories of Lamarck, under the name of NeoLamarckism, is undertaken, very largely, for the purpose of assigning the origin of variations to external causes, or to the environment, in opposition to those who consider the source of variation to be essentially innate or at least internal. But Darwin also believed that variation is induced by the environment, and the chief factor in this environment, so far as its reaction upon the organism is concerned, is probably excess of food supply, although climate, and other impinging circumstances, are potent causes of modification. He marshalled arguments to support "the view that variations of all kinds and degrees are directly or indirectly caused by the conditions of life to which each being, and more especially its ancestors, have been exposed," and that "each separate variation has its own proper exciting cause." I do not understand how it has come about that various writers declare that Darwin did not believe explicitly in the external cause of variation, and that they feel obliged to go back to Lamarck in order to find a hypothesis for the occasion. It is true that Darwin believed that the nature or direction or particular kind of variation in a given case, is determined very largely by the constitution of the organism, but variation itself, that is, variability, proceeds largely from external causes; and the characters arising in the lifetime of an in- dividual may become hereditary. I must hasten to explain, however, that Darwin clearly recognized the importance of the union of sexes, or crossing, as a cause of variation.

While Darwin believed that the effects of variability arise "generally from changed conditions acting during successive generations," he nevertheless believed that the first increment of change-that arising in the first individual of a given series - might be directly carried over to the first offspring. That is, he believed in the hereditability of acquired or new external characters, a fact which is emphasized by his conviction that certain mutilations, and even the effects of use and disuse, may be transmitted. Yet, whilst Darwin accepted the doctrine, he believed it much less thoroughly than Lamarck did, and it is but an incidental part of his philosophy, while it is an essential tenet of Lamarckism.

Thus far, the heriditability of all important characters had not been disputed. In other words, heredity as a general law or force in the organic world, had been assumed. But with the refinement of the discussions it became necessary to conceive of some definite means through which the transmission of particular characters or features should operate; and it was soon found, also, that no philosophy of evolution can expect to explain the phenomena of organic life unless it is connected and co-ordinated with some hypothesis of the method of heredity. While, therefore, a hypothesis of heredity need not necessarily be associated with the abstract theory of evolution, all such hypotheses which are now before the scientific world have for their particular object the explanation of the assumed progressive tendency of the forms of life.

It is incomprehensible that the minute fertilized ovum or ovule should reconstruct the essential characters of the two individuals from which it proceeds, unless it has in some way derived distinct impressions from every part and organ of the parental bodies which it reproduces. It would seem as if it must of itself be an epitome or condensation of its parents, with the power of unfolding its impressions or attributes during the whole life course of the organism to which it gives rise. Several hypotheses have been announced to account for the phenomena of heredity, of which, one of the most important is still Darwin's theory of pangenesis. Darwin supposed, provisionally, that besides the ordinary multiplication of the 
cell, each cell may "throw off minute granules which are dispersed throughout the whole system; that these, when supplied with proper nutriment, multiply by self-division, and are ultimately developed into units like those from which they were originally derived." These granules, or gemmules, have a natural affinity for each other, and they collect themselves "from all parts of the system" to form the sexual materials or elements. These sexual elements, therefore, which unite to form the new individual, are an epitomized compound of the parents. The value of this hypothesis, it seems to me, lies not so much in the particular constitution and behavior of these gemmules, as in the fact that it attempts to account for the known phenomena of life by supposing each corporeal element to be represented in the sexual elements. The hypothesis has never gained wide support, because of the supposed physical improbability of the gemmules and of their concentration in sexual system; yet it should be said that a simpler one, which can account for the facts, has not yet been advanced, unless it be the bathmic hypothesis of Cope, which supposes that each body-cell transmits "a mode of motion" to the germ-cell.

For the present purpose, we need consider but one other hypothesis of heredity - that advanced in 1883 by Weismann, which has given rise to the philosophy now called Neo-Darwinism. Weismann's point of view is interesting and unique. He places himself at the threshold of organic life and contemplates what takes place in the reproduction of onecelled organisms. These organisms multiply largely by simple division, or fission. When the organism reaches a certain size, it becomes constricted near its middle, and finally parts into two cells or organisms. It is evident that one organism is twin of the other, neither is older, neither is parent, but each has partaken of the common stock of protoplasm. The protoplasm again multiplies itself in the two organisms, and at length it is again divided; and so, to the end of time, the remotest individual of the series may be said to contain a portion of the original protoplasm; in other words, the protoplasm is continuous. And inasmuch as protoplasm is the seat or physical basis of life, it may be said that the one-celled organism is immortal, or is not confronted by natural death.

In time, however, there came a division of labor-cells living together in colonies, and certain cells performing one function and certain other cells other functions. This was, perhaps, the beginning of the many-celled organism, in which certain cells developed the specific function of reproduction, or eventually became elements of sex. As organisms became more complex in their structure, there came to be great differences between this reproductive or germ portion and the surrounding or body portion; and Weismann assumes that these two elements are different and distinct from each other in kind, and that inasmuch as the one-celled organisms propagated their exact kind by simple division, that therefore the reproductive elements of the many-celled or complex body must continue to perpetuate their kind or enjoy immortality, while all the surrounding or body cells die and are reproduced only through the reconstructive power of the sexual elements. There are, then, according to this hypothesis, two elements or plasms in every organized being, the germ-plasm and the soma-plasm or body-plasm; and every organism which procreates thereby preserves its germplasm to future generations, while death destroys the remainder. A vital point in this hypothesis is the method by which the soma-plasm, or the organs and body of the organism, can be so impressed upon the germ that they shall become hereditary. At first it would seem as if some assumption like that of Darwin's might be useful here-that this germplasm is impressed by particles thrown off from all the surrounding or soma-cells; but this Weismann considers to be too unwieldy, and he ascribes the transfer of these characters through the medium of the germplasm to "variations in its molecular constitution." In other words, there can be no heredity of a character which originates at the periphery of the individual, because there is no means of transferring its likeness to the germ. All modification of the offspring is predetermined in the germ-plasm; and if the new organism becomes modified through contact with external agencies, such modification is lost with the death of the individual. "Characters only acquired by the operation of external circumstances acting during the life of the individual, cannot be transmitted." "All the characters exhibited by the offspring are due to primary changes in the germ." It is admitted that the continued effect of impinging environment may, now and then, finally reach the germ-plasm, but not in the first generation in which such extraneous influence may be exercised. In other words, acquired characters cannot be hereditary. 
It would seem as if this hypothesis precluded the possibility of evolution or the continued modification of species, inasmuch as it does not accept the modifications arising directly from external sources. But Weismann supposes that variation originatesor at least all variation which is of permanent use to the species-from a union of the sexes, inasmuch as the unlike germ-plasms of two individuals unite ; and from the variations thus induced are derived the materials upon which natural selection works in the struggle for existence. "I am entirely convinced," Weismann writes, "that the higher development of the organic world was only rendered possible by the introduction of sexual reproduction." "Sexual reproduction has arisen by and for natural selection, as the only means by which the individual variations can be united and combined in every possible proportion."

It will be seen that Weismann is a Darwiniana believer in natural selection as the one controlling process of evolution; but, unlike Darwin, he refers variation to sex and declares that any new or acquired character originating in the body of the organism cannot be transmitted. The exact means or machinery through which he supposes heredity to act, is rather more an embryological matter than a philosophical one. We are particularly concerned in its results, which are the distinguishing marks of Neo-Darwinism - that variation is of sexual or internal origin, and that acquired characters are not hereditary.

In opposition to this body of belief, which has been upheld, particularly in England, with much aggressiveness, is Neo-Lamarckism, which is a compound of both Lamarckism and Darwinism, and which has an especially strong following in North America. The particular canons' of this philosophy are the belief that external causes, or the environment, are directly responsible for much variation and that acquired characters are often hereditary. Other features of it, held in varying degrees by different persons, are the belief in the transforming effects of use and disuse, and in natural selection.

The one great schism between the NeoDarwinians and the Neo-Lamarckians is the controversy over the hereditability of acquired characters, and just at present this question has come so strongly to the fore that other differences in the two hypotheses have been obscured. It is worthy of remark that Darwinism or Neo-Lamarckism sees first the facts or phenomena and then tries to explain them ; while Neo-Darwinism or Weismannism assumes first a hypothesis and then tries to prove it. I think that any one will be struck with this difference of attitude, if he read Darwin's chapter upon pangenesis, and then read Weismann's essay upon heredity. The Neo-Darwinians are loud in demand of facts or proof that acquired characters are hereditary, and they attempt to throw the burden of proof upon their opponents; while, at the same time, they give no proofs of their own position, and confound their adversaries with verbal subtleties. The burden of proof, however, lies clearly upon the Neo-Darwinians, inasmuch as they have assumed to deny phenomena which were theretofore considered to be established.

A voluminous issue of polemics has occurred during the last five or six years between the NeoDarwinians and the Neo-Lamarckians; but whatever may have been its effects upon the older philosophy, it is clear, to my mind, that some of the attacks upon Neo-Darwinism are unanswerable in any rational manner, and it is certain that they have forced Weismann into a change of position with reference to some of his definitions. Certain phases of this discussion appeal with particular force, of course, to some minds, while they exert little influence upon others. My own objections to Neo-Darwinism-and I admit that my bias is strong against it-seem to be somewhat different from those most commonly urged in opposition to it; and the three which chiefly influence me I shall present very briefly.

1. I cannot see that the non-transmissibility of acquired characters is a necessary assumption to Weismann's fundamental arguments. I have already explained his reasoning from the reproduction of the one-celled organism. I cannot attempt any opinion of the probable facts upon which the hypothesis is founded. It may be said, in passing, that one of the prominent objections to the fundamental basis of the theory is the difficulty of deriving the mortal somaplasm from the immortal germ-plasm, a question to which, however, Weismann has made a somewhat full reply.

When organisms became complex, it was necessary to assume either that the soma-plasm does or does not directly influence the germ-plasm. Weismann discarded the various hypotheses which suppose that there is a vital and necessary connection 
between the body units and reproductive units, and then to avoid the difficulties which the hereditability of acquired characters would entail, he supposed that such characters are not hereditary. His subsequent labors have been largely employed in trying to show that they are not. This supposition was made for the purpose of simplifying the hypothesis by removing the cumbrous gemmules of Darwin and the similar bodies or movements of other philosophers, and therefore by localizing the seat of the germ-plasm. But he immediately encounters difficulties quite as great as those which he avoids. In cases where there are alternate generations of asexual and sexual organisms, he must suppose that the germ-plasm is united with the soma-plasm, and is probably, therefore, distributed throughout the body. "There maybe in fact cases," Weismann writes, "in which such separation [of the germ-plasm from the somaplasm] does not take place until after the animal is completely formed, and others, as I believe that I have shown, in which it first arises one or two generations later, viz., in the buds produced by the parent." And he has been compelled to admit that in the case of begonias, which are propagated by leaves, the germ-plasm is probably distributed throughout the foliage ; and he must make a similar admission for all plants, for they can all be propagated and modified through asexual parts. This is admitting, then, that there is no localized germplasm in the vegetable kingdom and in some instances in the animal kingdom; and if the germ-plasm is distributed to the very periphery of the organism, why may it not be directly affected by environment, the same as the soma-plasm is? Or why is the hypothesis any the less objectionable than Darwin's pangenesis, which supposes that every organic unit can communicate with the germ?

Weismann also supposes, as I have said, that the means by which the germ-plasm is able to reconstruct the soma-plasm in the offspring, is through some modification in its "molecular constitution," an assumption which was by no means novel when Weismann announced it. "The exact manner in which we imagine the subsequent differentiation of the colony to be potentially present in the reproductive cell," he writes, "becomes a matter of comparatively small importance. It may consist in a different molecular arrangement, or in some change of chemical constitution, or it maybe due to both these causes combined." In whatever manner the germ- plasm receives its somatic, influences, there must be a direct connection between the two, and it is quite as easy to assume the existence of gemmules as any less tangible influence. I am not arguing in favor of pangenesis, but only stating what seems to me to be a valid objection to the fundamental constitution of the Weismannian hypothesis-that it is quite as easy to assume, from the argument, one interpretation of the process or means of heredity as another. And if there is any vital connection whatever between the soma-plasm and the germ-plasm - as the hypothesis itself must admit—then why cannot the soma-plasm directly influence the germ-plasm?

Again, I wish to point out that modification and evolution of vegetable species may and does proceed wholly without the interposition of sex-that is, by propagations through cuttings or layers of various parts. This proves either one of two things-that the germ-plasm is not necessary to the species, or else that it is not localized but distributed throughout the entire body of the individual, as I have shown above; and either horn of this dilemma is fatal, it seems to me, to Weismannism. If the germ-plasm is not necessary to this reproduction, then we must discard the hypothesis of the continuity of the germplasm; if the germ-plasm is distributed throughout the plant, then we are obliged to admit that it is not localized in germ-cells beyond the reach of direct external influences.

This sexual propagation of plants has been brought to Weismann's attention by Strasburger, who cited the instance of the leaf-propagation of begonia, and said that plants thus asexually multiplied afterwards produce flowers and seeds, or develop germ-plasm. Weismann meets the objection by supposing that it is pqssible for "all somatic nuclei to contain a minute fraction of unchanged germplasm," but he considers the begonia, apparently, to be an exception to most other plants, inasmuch as he declares that "no one has ever grown a tree from the leaf of the lime or oak, or a flowering plant from the leaf of the tulip or convolvulus." Henslow meets this latter statement by saying that this has not been accomplished simply because "it has never been worth while to do it. If, however, a premium were offered for tulips or oak-trees raised from leafcuttings, plenty would soon be forthcoming." What Weismann wishes to show is that the begonia is an exception to other plants in allowing of propagation 
from leaf-cuttings, although he should have known that hundreds of plants can be multiplied in this way, and that - what amounts to the same thing —all plants can be propagated by asexual parts, as stems or roots.

But there is another aspect to this asexual multiplication of plants which I do not remember to have seen stated in this connection. It has been said that the asexually multiplied plants may afterwards produce flowers and resume the normal method of reproduction and variation. I now wish to add what I have already said, that plants may be continuously multiplied asexually and yet the offspring may vary, and the variations may be transmitted from generation to generation, quite as perfectly as if seed production intervened. This has been true with certain plants through a long period of time, as the banana, and every intelligent gardener knows that plants propagated by cuttings often "sport" or vary. Here are cases, then, in which variation does not originate from sex, unless Weismann is willing to concede that the result of previous sexual union has remained latent through any number of generations and has been carried to all parts of the plant by a generally diffused germ-plasm; and if this is admitted, then I must again insist that this germ-plasm must be just as amenable to external influences as the somaplasm with which it is indissolubly associated. I have repeated this argument in order to introduce the subject of "bud variations," or those "sports" which now and then appear upon certain limbs or parts of plants and which are nearly always readily propagated by cuttings. These variations cannot be attributed to sex, in the ordinary and legitimate application of the Weismann ian hypothesis. Whilst these "sports" are well known to horticulturists, they are generally considered to be rare, but nothing can be farther from the truth. As a matter of fact, every branch of a tree is different from every other branch, and when the difference is sufficient to attract attention, or to have commercial value, it is propagated and called a "sport." This leads me to recall the old discussion of the phytomer, or the hypothesis that every node and internode of a tree-and we might add the rootsis in reality a distinct individual, inasmuch as it possesses the power of leading an independent existence when severed from the plant, and of reproducing its kind. However this may be as a matter of of speculation, it is certainly true as regards the phe- nomenon, and shows conclusively that if the germplasm exists at all, it exists throughout the entire structure of the plant. This conclusion is also unavoidable from another consideration - the fact that plants are asexual organisms at all times previous to flowering, and the germ-plasm must be preserved, in the meantime, along with the soma-plasm. But this conclusion is inconsistent with Weismannism as taught at present, and this alone would lead me to discard the hypothesis for plants, however well it may apply to the animal kingdom.

Henslow has made a different argument to show that the germ-plasm of plants may be directly exposed to external influence (Origin of Floral Structures). The germ-plasm is assumably located in the flower, and the egg-cell of the embryo-sac and the sperm-cell of the pollen grain are close to the surface, and are directly impressed by the interference of bees and other external stimuli. Henslow endeavors to show "that the infinite variety of adaptations to insects discoverable in flowers may have resulted through the direct action of the insects themselves, coupled with the responsive power of protoplasm." And these characters must be in part acquired during the lifetime of a given individual.

2. It seems to me, also, that the presumption, upon general philosophical grounds, is against the doctrine that immediate external influences are without permanent effect. If we admit-as all philosophers now do-that species are mutable, and that the forms of life have been shaped with reference to their adaptations to environment, then we are justified in assuming that every change in that environment must awaken some vital response in the species. If this response does not follow, then environment is without influence upon the organism; or if it follows and is then not transmitted, it is lost just the same, and environment is impotent. And it does not matter if we assume, with the Neo-Darwinians, that this effect does not become hereditary until the germ is affected-that is, until two or more generations have lived under the impinging environmentit must nevertheless follow that the change must have had a definite beginning in the lifetime of an individual; for it is impossible to conceive that a change has its origin in two generations. In other words, the beginning is singular; two generations is plural. And whether the modification is directly visible in the body of the organism or is an intangible force 
impressed upon the germ, it is nevertheless an environmental character, and was at first acquired. If this is not true - that the changed conditions of life exert a direct effect upon the phylogeny of the speciesthen no variation is possible save that which comes from the recompounding of the original or ancestral sex-elements; and it would still be a question how these sex-elements acquired their initial divergence.

The Neo-Darwinians would undoubtedly meet this argument by saying that their hypothesis fully admits the importance of these external influences, the only reservation being that they shall have affected the germ. It is true that this is a common means of escape; but it cannot be gainsaid that the denial of the influence of the external or environmental forces is really the fundamental difference between them and the Darwinians or Neo-Lamarckians, as the following quotation from Weismann will show: "Our object is to decide whether changes in the soma (the body, as opposed to the germ-cells) which have been produced by the direct action of external influences, including use and disuse, can be transmitted; whether they can influence the germ-cells in such a manner that the latter will cause the spontaneous appearance of corresponding changes in the next generation. This is the question which demands an answer; and, as has been shown above, such an answer would decide whether the Lamarckian principles of transformation must be retained or abandoned."

If, then, to repeat, organisms are adapted to their environment, it must be equally true that this environment directly affects its inhabitants ; and considering the intense struggle for existence under which all organisms live, it is highly probable that any advantageous variation can be seized upon at once. I cannot conceive that nature allows herself to lose the result of any effort.

3. My third conviction against Neo-Darwinism arises from the fact that its advocates are constantly explaining away the arguments of their opponents by verbal mystifications and ingenious definitions. This charge is so frequently made, and the fact is so well known, that it seems almost useless to refer to it here ; and yet there are some phases of it upon which I cannot forbear to touch.

Weismann declares that he uses the term "acquired character" in its original sense. This term, or at least the idea, was first employed, as we have seen, by Lamarck, who used it or an equivalent phrase to designate "every change acquired in an organ by a habitual exercise sufficient to have brought it about." In fact, the basis of Lamarck's philosophy is the assumption of the hereditability of characters arising directly from use or disuse; and his idea of an acquired character is, therefore, one which appears in the lifetime of the individual from some externally inciting cause. Darwin's notion, while less clearly defined, was essentially the same, and he collected a mass of evidence to show that such characters are transmissible; and he even went farther than Lamarck, and attempted to show that mutilations may be hereditary. Weismann's early definition of acquired characters is plain enough. Such characters, that is, the somatogenic, "not only include the effects of mutilation, but the changes which follow from increased or diminished performance of function, and those which are directly due to nutrition and any of the other external influences which act upon the body." Standing fairly and squarely upon this definition, it is easy enough to disprove it - that is, to show that some characters thus acquired are hereditary. But the moment proofs are advanced, the definition is contracted, and the Neo-Darwinians declare that the given character was potentially present in the germ and was not primarily superinduced by the external conditions-a position which, while it allows of no proof, can neither be overthrown. A cow lost her left horn by suppuration, and two of her calves had rudimentary left horns; but Weismann immediately says, "The loss of a cow's horn may have arisen from a congenital malformation." Certainly! and it may not; and the presumption is that it did not. A soldier loses his left eye by inflammation, and two of his sons have defective left eyes. Now, "the soldier," says Weismann, "did not lose his left eye because it was injured, but because it was predisposed to become diseased from the beginning, and readily became inflamed after a slight injury"! This gratuitous manner of explaining away the recorded instances of the supposed transmission of mutilations and the like, is common with the NeoDarwinians, but it must always create the impression, it seems to me, of being labored and far-fetched; and inasmuch as it is incapable of proof, and is of no occasion beyond the mere point of upholding an assumed hypothesis, it is scarcely worthy serious attention. It would be far better for the Neo-Darwinians if they would flatly refuse to accept the statements concerning the transmission of mutilations, rather than to 
attempt any mere captious explanation of them; for it is yet very doubtful if the recorded instances of such transmissions will stand careful investigation.

But perhaps the most remarkable example of this species of Neo-Darwinian logic is produced by Weismann when he is hard pressed by Hoffmann, who supposed that he had proved the hereditability of certain acquired characters in poppies. Weismann says: "Since the characters of which Hoffmann speaks are hereditary, the term cannot be rightly applied to them;" thus showing that his fundamental conception of an acquired character is one which cannot be transmitted! He then proceeds to elaborate this definition as follows: "I have never doubted about the transmission of changes which depend upon an alteration in the germ-plasm of the reproductive cells, for I have always asserted that these changes, and these alone, must be transmitted." Then he proceeds to say that it is necessary to have "two terms which distinguish sharply between the two chief groups of characters-the primary characters which first appear in the body itself, and the secondary ones which owe their appearance to variations in the germ, however such variations may have arisen." We have hitherto been accustomed to call the former 'acquired characters', but we might also call them 'somatogenic,' because they follow from the reaction of the soma under external influences; while all other characters might be contrasted as 'blastogenic', because they include all those characters in the body which have arisen from changes in the germ. ${ }^{*} * *$ We maintain that the 'somatogenic' characters cannot be transmitted, or rather, that those who assert that they can be transmitted, must furnish the requisite proofs. "That is: changes in the soma-plasm are not transmitted; acquired characters are changes in the soma-plasm; therefore, acquired characters cannot be transmitted! Or, to use Weismann's shorter phrase, "Since the characters ${ }^{* * *}$ are hereditary, the term ['acquired'] cannot be rightly applied to them!"
Surely, Neo-Darwinism is impregnable!

Weismannism has unquestionably done much to elucidate some of the most intricate questions of biology, and it has weeded the old hypotheses of much that was ill-considered and false. It has challenged beliefs which have been too easily accepted. Its value to the science of heredity upon its biological side is admitted, and its explanation of the meaning of sex is one of the best of all contributions to the philosophy of organic nature. It has suffered, perhaps, from too ardent champions, and its great weakness lies in its stubborn refusal to accept an important class of phenomena associated with acquired characters, a sufficient explanation of which, it seems to me, could be assumed without great violence to the hypothesis.

Most Neo-Lamarckians accept much of Weismann's teachings. But, while there are comparatively few who believe that mutilations are directly transmissible, there is a general and strong conviction that many truly acquired characters are hereditary, and there seems to be demonstrable evidence of it; and while sex variation is fully accepted, it logically follows, if acquired characters are hereditary, that much variation is due directly to external causes. Perhaps the habit of thought of most Darwinians and NeoLamarckians is something as follows:

All forms of life are mutable. Variation affords the material from which progress is derived. Variation is due to sexual union, changed conditions of life, panmixia or the cessation of natural selection, and probably somewhat to direct use and disuse. There is an intense struggle for existence. All forms or variations useful to the species tend to live, and the harmful ones tend to be destroyed through the operation of the simple agent of natural selection. These newly appearing forms tend to become permanent, sometimes immediately; but the longer the transforming environments are present, the greater is the probability, on the whole, that the resulting modifications will persist. 